\title{
The introduction of an international model to reduce injuries in Rugby Union in South Africa
}

\author{
James Craig Brown (MSc) \\ MRC/UCT Research Unit for Exercise Science and Sports Medicine, Department of Human Biology, University of Cape Town
}

Regular participation in physical exercise or sport is popular due to the numerous health benefits it offers to the individual. ${ }^{1}$ However, these potential benefits need to be offset against the magnitude of risk of injury that participating in the activity may present to the individual. The risk/benefit ratio varies depending on the type of activity. ${ }^{1}$ In terms of major male-dominated sports, Rugby Union presents a high risk of overall injury to the player - greater than that of cricket, soccer or even ice hockey. ${ }^{2}$ The high incidence of injury in rugby is related to the nature of the game - a field-based team sport that involves multiple contact situations over the 80 minutes of play. ${ }^{3}$ Considering the popularity of the sport, with an estimated 92 countries participating worldwide, this injury risk presents a significant global issue. $^{3}$ From the inception of the game of Rugby Union, which is speculated to have been between the start of the 1600 s and the mid 1800s, the game has been regarded as a violent sport and the formation of the Rugby Football Union in 1871 was necessitated, in part, by the need for laws to reduce this violence. ${ }^{4}$

The laws of Rugby Union have developed exponentially in both number and complexity from these amateur beginnings to the game's professional present. Subsequent law development has not only had the motive of reducing unnecessary injury, ${ }^{5}$ but also to distinguish Rugby Union from other codes of Rugby and from 'simpler' games that were thought to be for the common working classes. ${ }^{4}$ Despite this exclusivity, Rugby Union, like all other sports, was forced to compete with other sports for spectators. ${ }^{4}$ As a result, from as early as the 1876 - 1877 season, in which the Rugby Football Union (RFU) reduced the number of players on the field from 300 to 30 , there have been numerous examples of law changes that were brought about to enhance spectator gratification. The result - a faster, more open, running game - is believed to be associated with an increased risk of injury due to the greater speed and frequency of physical contacts. ${ }^{6}$

Of all sports injuries, those with catastrophic outcomes are the most life-altering, both for the sufferer and for their immediate family and friends. While media reports often closely associate Rugby Union with catastrophic injuries, ${ }^{7}$ the actual risk of sustaining these types of injuries while playing Rugby is low in comparison to other sports (diving and horse-riding) and even everyday activities (driving or walking to work). ${ }^{8}$ Despite this contextual perspective, the consequences of catastrophic injuries are such that even one case

\section{CORRESPONDENCE:}

James Brown

Department of Human Biology

University of Cape Town

Tel: $021650-4572$

Fax:021 686-7530

E-mail: James.Brown@uct.ac.za a year as a result of participating in rugby is one case too many. In South Africa, the stories of the tragic deaths of Chris Burger and Petro Jackson, as well as the many rugby players supported by their memorial Fund (Chris Burger Petro Jackson Players' Fund), bears testament to this statement. ${ }^{9}$

Owing to the high risk of injury, either in incidence or severity, that Rugby Union poses to the player, epidemiological researchers have been investigating this sport extensively since $1954 .^{10}$ Researchers in New Zealand not only accurately described the incidence of injuries in rugby, but also developed and evaluated an injury prevention programme that sought to reduce the incidence of injury. ${ }^{11}$ The programme, known as RugbySmart, chose to educate coaches and referees about best practices to reduce the risk of injury, assuming that these key stakeholders would disseminate their knowledge and behaviour to their players. In the evaluation of the programme, ${ }^{12}$ RugbySmart was found to be effective not only in reducing the incidence of both general and catastrophic injury, but also in improving rugby players' knowledge and behaviour with regards to injury risk factors over the course of 5 years.

The sport of Rugby Union is also particularly popular in South Africa, with an estimated $400000-500000$ players nationwide. ${ }^{13}$ Despite the high level of participation, there have been few wellperformed prospective epidemiological studies on rugby in South Africa. Of concern are the estimates of catastrophic injury that are available since 2001, largely as a result of the Chris Burger Petro Jackson Player's Fund, which suggest an average of 22 catastrophic injuries per annum in South Africa. ${ }^{13}$

This concern about catastrophic injuries resulted in the RugbySmart intervention programme being adapted, with permission, for the South African context. The South African programme, BokSmart, was launched in July 2009. Despite vast differences between New Zealand and South Africa in the context of implementation of this programme, more than 25000 coaches and referees have already been educated about the principles of safety in rugby in South Africa. The next important step is to determine whether the knowledge of the coaches and referees who have undergone training in South Africa translates into behaviour that reduces the incidence and severity of rugby-related injuries.

\section{REFERENCES}

1. Van Mechelen W, Hlobil H, Kemper HC. Incidence, severity, aetiology and prevention of sports injuries. A review of concepts. Sports Med 1992;14(2):82-99.

2. Fuller $\mathrm{C}$, Drawer $\mathrm{S}$. The application of risk management in sport. Sports Med 2004;34(6):349-356.

3. Duthie G, Pyne D, Hooper S. Applied physiology and game analysis of rugby union. Sports Med 2003;33(13):973-991.

4. Richards H. A game for hooligans. The History of Rugby Union. Edinburgh: Mainstrean Publishing Company, 2007.

5. Burry HC, Calcinai CJ. The need to make rugby safer. Br Med J (Clin Res Ed) 1988;296(6616):149-150.

6. Noakes TD, Du Plessis M. Rugby without risk. A Practical Guide to the Prevention and Treatment of Rugby Injuries. Pretoria: Van Schaik, 1996. 
7. Quarrie KL, Cantu RC, Chalmers DJ. Rugby union injuries to the cervical spine and spinal cord. Sports Med 2002;32(10):633-653.

8. Fuller CW. Catastrophic injury in rugby union: is the level of risk acceptable? Sports Med 2008;38(12):975-986.

9. Tebbutt P. Samaritan of South African Rugby. SUN PReSS, 2010

10. O'Connell TC. Rugby football injuries and their prevention; a review of 600 cases. J Ir Med Assoc 1954;34(199):20-26.

11. Quarrie KL. RugbySmart: The Development, Delivery and Evaluation of a Nationwide Sports Injury Prevention Programme. Auckland University of Technology, 2008.
12. Gianotti SM, Quarrie KL, Hume PA. Evaluation of RugbySmart: a rugby union community injury prevention programme. J Sci Med Sport 2009;12(3):371-375

13. SA Rugby Website, 2009. BokSmart National Rugby Safety Program. Available at: http://www.sarugby.co.za/boksmart/default.aspx (accessed 16 March 2011). 